\section{Genetic variation of brain-derived neurotrophic factor (BDNF) in bipolar disorder}

\author{
Case-control study of over 3000 individuals from the UK
}

\author{
ELAINE K. GREEN, RACHEL RAYBOULD, STUART MACGREGOR, \\ SALLY HYDE, ALLAN H. YOUNG, MICHAEL C. O'DONOVAN, \\ MICHAEL J. OWEN, GEORGE KIROV, LISA JONES, IAN JONES \\ and NICK CR ADDOCK
}

\begin{abstract}
Background Brain-derived neurotrophic factor (BDNF) influences neuronal survival, proliferation and plasticity. Three family-based studies have shown association of the common Valine ( Val) allele of the $\mathrm{Val66Met}$ polymorphism of the BDNF gene with susceptibility to bipolar disorder.
\end{abstract}

Aims To replicate this finding.

Method We genotyped the Val66Met polymorphism in our UK White bipolar case-control sample $(n=3062)$.

Results We found no overall evidence of allele or genotype association. However, we found association with disease status in the subset of 131 individuals that had experienced rapid cycling at some time $(P=0.004)$.We found a similar association on re-analysis of our previously reported family-based association sample $(P<0.03$, one-tailed test).

Conclusions Variation at the Val66Met polymorphism of BDNF does not play a major role in influencing susceptibility to bipolar disorder as a whole, but is associated with susceptibility to the rapidcycling subset of the disorder.

\section{Declaration of interest N.C. and \\ M.J.O. are consultants to GlaxoSmith Kline and have received grant funding and honoraria from GlaxoSmith Kline, AstraZeneca and Eli Lilly. M.C.O'D., A.H.Y., L.J. and G.K. have received honoraria from GlaxoSmith Kline, AstraZeneca and Eli Lilly.G.K. has received grant funding from Janssen. Funding detailed in Acknowledgements.}

There is compelling evidence that genetic factors are important in determining susceptibility to bipolar disorder (Craddock \& Jones, 1999; Craddock et al, 2005). A functional candidate gene that has attracted a great deal of recent interest is that encoding brain derived neurotrophic factor (BDNF) (Green \& Craddock, 2004) and it has been hypothesised that mania may be caused by overactivity of central BDNF function (Tsai, 2004). There have been three family-based studies of bipolar samples of European-American origin reporting an association of the Val66Met polymorphism with bipolar disorder - two are in adult bipolar samples (Neves-Pereira et al, 2002; Sklar et al, 2002) and one is of a small childhood-onset sample (Geller et al, 2004). All have shown overtransmission of the common Valine (Val) allele. We have attempted to replicate these findings and to explore possible phenotypic specificity for the association.

\section{METHOD}

\section{Participants}

All participants were of UK origin and White and provided written informed consent for genetic studies. Protocols and procedures were approved by relevant ethics review panels, including the UK West Midlands Multi-Centre Research Ethics Committee.

\section{Probands with bipolar disorder}

Individuals were recruited through mental health services in England and Wales and met DSM-IV (American Psychiatric Association, 1994) criteria for bipolar I disorder $(n=864,37 \%$ male, mean age $=48$ years (s.d.=13)) or bipolar II disorder $(n=98$, $39 \%$ male, mean age $=52$ years $($ s.d. $=13)$ ). Diagnoses were made by the consensus lifetime best-estimate method (Leckman $e t$ al, 1982) on the basis of all available information, including a semi-structured interview (Schedules for Clinical Assessment in Neuropsychiatry, SCAN; Wing et al, 1990), Diagnostic Interview for Genetic Studies (DIGS; Nurnburger et al, 1994) or Schedule for Affective Disorders and Schizophrenia - Lifetime Version (SADS-L; Endicott \& Spitzer, 1978) and review of psychiatric case records and an OPCRIT checklist (McGuffin et al, 1991). Key clinical variables relating to psychosis were rated using the Bipolar Affective Disorder Dimensional Scale (BADDS; Craddock et al, 2004). Our sample of people with bipolar disorder had a lifetime occurrence of one or more psychotic features in $56 \%$ of those with bipolar I disorder and $18 \%$ of those with bipolar II disorder. Other key clinical variables were rated according to written operational guidelines in use by our group and available on request from the authors. These included age at onset of impairment by illness (those with bipolar I disorder, mean age at onset $=26$ years (s.d.=10); those with bipolar II disorder, mean age at onset $=30$ years $($ s.d. $=13)$ ), family history of psychiatric illness (history of psychiatric illness in first- or seconddegree relative: those with bipolar I disorder $71 \%$; those with bipolar II disorder, $76 \%$ ), definite lifetime occurrence of rapid cycling (defined as at least one period of 12 months during which four or more distinct episodes of major mood disorder occurred; present in $13 \%$ of those with bipolar I and $18 \%$ of those with bipolar II disorder) and definite lifetime occurrence of postpartum triggering of psychotic major affective episodes (present in $14 \%$ of those with bipolar I and 3\% those with bipolar II disorder). Team members involved in the interview, rating and diagnostic procedures were either a fully trained research psychologist or a psychiatrist. Interrater reliability was high. This was formally assessed using 20 cases and resulted in a mean kappa statistic of 0.85 for DSM-IV diagnosis. Mean kappa for the key clinical variables ranged from 0.81 to 0.99 . Formative clinical team reliability meetings took place weekly.

\section{Control individuals}

Controls $(n=2100,47 \%$ male, mean age $=42.2$ years $($ s.d. $=11.2))$, all White and of UK origin, were from three sources:

(a) The British Blood Transfusion Service $(n=1012)$. This sample was not specifically screened for psychiatric illness but individuals were not taking regular prescribed medications. In the 
Table I Allele and genotype distributions at the BDNF Val66Met polymorphism in people with bipolar disorder and controls

\begin{tabular}{|c|c|c|c|c|c|c|c|c|}
\hline Phenotype & $\begin{array}{c}\text { Val allele, } \\
\text { counts } \\
\text { (frequency) }\end{array}$ & $\begin{array}{c}\text { Met allele, } \\
\text { counts } \\
\text { (frequency) }\end{array}$ & $\begin{array}{l}\text { Odds ratio } \\
(95 \% \mathrm{Cl})\end{array}$ & $\chi^{2}(\text { d.f., } P)^{2}$ & $\begin{array}{l}\text { Val/Val geno- } \\
\text { type, counts } \\
\text { (frequency) }\end{array}$ & $\begin{array}{c}\text { Val/Met geno- } \\
\text { type, counts } \\
\text { (frequency) }\end{array}$ & $\begin{array}{c}\text { Met/Met geno- } \\
\text { type, counts } \\
\text { (frequency) }\end{array}$ & $\chi^{2}(\text { d.f., } P)^{2}$ \\
\hline Controls $(n=2100)$ & $3404(0.810)$ & $796(0.190)$ & - & - & $1372(0.654)$ & $660(0.314)$ & $68(0.032)$ & - \\
\hline Bipolar I and II disorder $(n=962)$ & $1577(0.820)$ & $347(0.180)$ & $\mathrm{I} .07(0.92-\mathrm{I} .22)$ & $0.73(I, 0.39)$ & $644(0.669)$ & $289(0.30 I)$ & $29(0.030)$ & $0.77(2,0.68)$ \\
\hline Bipolar I disorder $(n=864)$ & $1418(0.821)$ & $310(0.179)$ & $\mathrm{I} .07(0.93-1.24)$ & $0.83(I, 0.36)$ & $580(0.67 I)$ & $258(0.299)$ & $26(0.030)$ & $0.89(2,0.64)$ \\
\hline Bipolar II disorder $(n=98)$ & $159(0.811)$ & $37(0.189)$ & $\mathrm{I} .00(0.70-\mathrm{I} .45)$ & $0.00(I, 0.98)$ & $64(0.653)$ & $31(0.316)$ & $3(0.031)$ & $0.09(2,0.96)$ \\
\hline $\begin{array}{l}\text { Rapid-cycling bipolar disorder } \\
(n=|3|)\end{array}$ & $231(0.882)$ & $31(0.118)$ & $1.74(1.19-2.56)$ & $8.28(1,0.0040)$ & 101 (0.77I) & $29(0.221)$ & $\mathrm{I}(0.008)$ & $8.47(2,0.015)$ \\
\hline
\end{tabular}

Val, valine; Met, methionine.

I. Diagnoses are made according to DSM-IV.

2. $\chi^{2}$ and $P$ values refer to comparisons against the total control sample.

UK blood donors are not remunerated even for expenses and are, therefore, not over-represented for indigents or the socially disadvantaged in whom the rate of major psychiatric disorder might possibly rise above a threshold that would influence power (Moskvina et al, 2005).

(b) Family practitioner clinic $(n=110)$. Individuals were recruited in South Wales from among those attending a family practitioner clinic for nonpsychiatric reasons. This sample was screened to exclude a personal history of mood disorder.

(c) Members of the UK 1958 birth cohort epidemiological sample $(n=978)$ from the UK National Child Development Study. This is a continuing, multidisciplinary longitudinal study of all those living in Great Britain who were born in a particular week in March 1958 (http://www.cls.ioe.ac.uk/studies. asp? section $=000100020003$ ). Individuals comprised the first panel of this sample released for use as controls in DNA studies. All members were born in 1958 in the UK and are White; $50 \%$ of the sample are male.

\section{Genotyping}

The Val66Met polymorphism was genotyped using a fluorescence polarisation primer extension assay (Chen et al, 1999), using the AcycloPrime Kit (Perkin Elmer, Wellesley, Massachusetts, USA) according to the manufacturer's instructions and an Analyst genotyping platform (LJL Biosystems, Sunnyvale, California, USA).

\section{Statistics}

\section{Case-control data}

Departure from Hardy-Weinberg equilibrium was tested using a $\chi^{2}$ goodness-offit test. Tests for differences between allele and genotype frequencies were performed using Pearson $\chi^{2}$ analysis of contingency tables. Two-tailed $P$ values are reported. In addition to analysing data according to diagnostic group we also performed analyses in the following subsets of patients with bipolar disorder: (a) lifetime presence of psychotic features; (b) predominantly mood-incongruent psychotic features; (c) age at onset of impairment by illness before 20 years; (d) lifetime occurrence of rapid cycling; (e) lifetime occurrence of postpartum triggering of episodes and family history of psychiatric illness (i.e. bipolar affective puerperal psychosis); (f) family history of psychiatric illness in a first- or second-degree relative. Adjustment for multiple testing was made using Bonferroni correction.

\section{Re-analysis of family-based association sample}

A specific hypothesis was tested in a phenotypic subset of the previously published UK family-based association sample (Sklar et $a l, 2002)$ using the transmission disequilibrium test (Spielman et al, 1993). Both one- and two-tailed $P$ values are provided.

\section{Power estimation}

The power of our full sample to detect an effect of a magnitude similar to those previously reported in adult samples (Neves-Pereira et al, 2002; Sklar et al, 2002) was estimated using the Genetic
Power Calculator (Purcell et al, 2003) under the assumption of a multiplicative model. The power in the bipolar I disorder sample at a critical significance level, $P<0.05$, exceeded $92 \%$ for an effect of odds ratios (ORs) $>1.3$. For the effect size estimated in our own bipolar I family-based association sample $(\mathrm{OR}=1.19$; Sklar et al, 2002) our power to replicate this effect in the present study at this test size was $68 \%$.

\section{RESULTS}

There were no significant deviations from Hardy-Weinberg equilibrium in either the separate control sets or in the pooled control set. The allele frequencies showed no significant difference between the individual control sets and there was no evidence for any effect of age or gender of controls upon the distributions. Pooling the controls yielded a total sample of 2100 typed for Val66Met. Results for analysis of Val66Met genotyping in the bipolar disorder case-control sample are presented in Table 1. No differences in allele or genotype frequencies were seen between cases and controls for any of the diagnostic groups (bipolar I disorder, bipolar II disorder, bipolar disorder, see Table 1).

For the subset of 131 patients with bipolar disorder who had experienced at least one period of 12 months that met DSM-IV criteria for rapid cycling, we found a significantly increased frequency of the Val allele compared with controls $(88.2 \% v .81 .0 \%$, $\mathrm{OR}=1.74,95 \%$ CI $1.19-2.56, P=0.004$ uncorrected for multiple testing, $P=0.036$ with Bonferroni correction for testing the main diagnostic categories and six subtypes, see Table 1). We found no evidence 
for association for any of the other subtypes examined (data not shown).

\section{DISCUSSION}

\section{Bipolar disorder as a whole}

Our primary analysis of diagnostic category failed to find significant evidence for association of bipolar disorder with the Val allele of the Val66Met polymorphism of the BDNF gene. Our study, the largest case-control sample reported to date in bipolar disorder, is well powered to detect effects of the size reported in the three positive studies (power $>92 \%$ for effects with ORs $>1.3$ ). We can thus be confident that this polymorphism does not play an important role in influencing susceptibility to bipolar disorder in general, at least within the UK population studied. There have been six other case-control association studies (three in European samples (Oswald et al, 2004; Skibinska et al, 2004; Neves-Pereira et al, 2005), one in a Chinese sample (Hong et al, 2003) and two in samples of Japanese origin (Nakata et al, 2003; Kunugi et al, 2004)). None has demonstrated significant evidence for allelic or genotypic association. Our findings are thus consistent with these studies, although it should be noted that: (a) three of these studies were in non-European populations where effect sizes may vary from those in populations of European origin; and (b) the sample sizes, and hence power, in most of these previous studies were substantially smaller than in the present study - our sample is 3-5 times larger than most of the casecontrol and family-based samples used to date and over $50 \%$ larger than the largest of these. It is important to recognise that our findings do not exclude the whole $B D N F$ gene from having an important involvement in susceptibility to bipolar disorder. We chose the Val66Met polymorphism for study because it is the only known functional variant and because of previous work. However, it is possible that variation elsewhere within coding or control regions of the gene may be involved. To exclude this possibility systematic and detailed study of variation across the whole gene is required, together with testing variants within appropriately powered samples, such as in the current study.

\section{Rapid-cycling bipolar disorder}

One reason for discrepancy between studies might be phenotypic heterogeneity. Therefore we undertook a set of analyses within phenotypic subsets of our patient sample to explore the possibility that variation at the Val66Met polymorphism was associated with one or more specific aspects of the range of phenotypic complexity commonly seen in bipolar disorder. We found significant evidence that lifetime occurrence of at least one 12-month period of rapid cycling was associated with possession of the common Val allele (nominal significance $P=0.0040$ ), a finding that remained significant after Bonferroni correction $(P=0.036)$.

There was evidence for a dosage effect of the Val allele. When comparing the effect sizes, as measured by the genotypic ORs, the estimated effect size was larger for the $\mathrm{Val} /$ Val homozygote $(\mathrm{OR}=5.01,95 \% \mathrm{CI}$ 0.69-36.43) than for the Val/Met heterozygote $(\mathrm{OR}=2.99,95 \% \mathrm{CI}$ 0.40-22.28).

Our own UK family-based sample of 145 parent-offspring triads was included in the first of the family-based association studies to show evidence for association (Sklar et al, 2002); our sample showed a non-significant modest excess of transmission of the Val allele to affected offspring. When we tested for the presence of an effect of rapid cycling in our original familybased association sample, we found evidence for the same association of the Val allele with rapid cycling. There were only seven informative transmissions to bipolar probands with lifetime rapid cycling, but among these the Val allele was transmitted on six occasions and the Met allele on only one occasion (data not shown). Although the number of observations was small, this approached conventional levels of statistical significance $(P<0.059)$ under a twotailed test. Given that a specific direction of effect was hypothesised (i.e. overtransmission of the Val allele) one can make a case for use of a one-tailed test. This was significant at $P<0.03$.

It is of great interest that a similar finding has been observed in an independent sample. Müller et al $(2004,2006)$ have examined phenotypic subtypes within their family-based association sample in which they originally reported association (Neves-Pereira et al, 2002) and found that rapid-cycling cases explained the association originally observed. This provides confidence that our finding is robust and generalisable to other samples of European origin.

Within our study we have used the DSM-IV (American Psychiatric Association, 1994) definition of definite rapid cycling: four or more distinct episodes of major affective disorder within a 12-month period such that consecutive distinct episodes are either switches of pole or are separated by at least a 2-month period of euthymia. A participant was classified as a member of the lifetime rapid-cycling subset if they had ever experienced a 12-month period during which the DSM-IV criteria for rapid cycling were fulfilled. The DSM-IV definition is similar to the original definition of rapid cycling proposed by Dunner $\&$ Fieve (1974), but there has been a wide range of variations in definition used in the research and clinical literature (Maj et al, 1999; Mackin \& Young, 2004) and there is little consistency in the literature regarding a unified core concept of rapid cycling or what features constitute the essence of rapid cycling (MacKinnon et al, 2003). An important question, therefore, arises as to what specific features of bipolar illness are captured by the definition of rapid cycling used. Observed genetic association might be strongest for one or more phenotypic variables that are components of the rapid cycling concept or that have been described to distinguish patients with rapid cycling from those with non-rapid cycling. Such possibilities include gender, episode frequency, age at onset, duration of illness or severity of episodes. However, post hoc consideration of these variables using a logistic regression model failed to demonstrate any variable that was superior to the rapid-cycling category as a predictor (data not shown). Further studies of large data-sets will be required to explore the core clinical features of rapid mood changes associated with variation at $B D N F$.

\section{Methodological issues}

In any case-control study spurious differences between cases and controls that are unrelated to disease status can be caused by the presence of so-called population structure, which may result in differential sampling of cases and controls from genetically distinct sub-populations. However, we can be confident that this is unlikely to be the cause of our findings because: (a) both case and control samples were from the UK White population; (b) allele frequencies were similar between the three control groups and genotype distributions were consistent with Hardy-Weinberg equilibrium for the groups separately and pooled together, suggesting absence of substantial variation in genotype frequency 
across the population; (c) we observed a similar effect in our family-based sample which is robust to population stratification; (d) a similar effect has been observed in an independent family-based sample (Müller et al, 2004, 2006), which again is robust to population stratification.

In case-control studies it is important that appropriate controls are chosen for the patient sample. The ideal is to have an epidemiological design in which each control is sampled from precisely the same population as the patients, with all relevant variables being measured and allowed for in analysis. This is rarely achievable. In our study we have used three different sets of controls sampled in different ways. The different sets are similar in the distribution of $B D N F$ alleles and genotypes, which gives confidence that the differences observed between (pooled) controls and the cases of rapid-cycling bipolar disorder are phenotype-driven rather than a spurious effect of an unusual control set. The controls may either be screened to exclude illness ('supernormal') or unscreened. The former is generally more powerful and the latter more useful for estimating populationlevel effects. In the current study control sets, blood donors and members of the 1958 birth cohort were unscreened whereas those recruited from a family practitioner clinic were screened. For bipolar disorder, which has a population lifetime risk of approximately $1 \%$, the use of unscreened controls has a negligible effect on power (Moskvina et al, 2005).

\section{Brain-derived neurotrophic factor and mood disorder}

Brain-derived neurotrophic factor, a member of the neurotrophin superfamily, is a highly plausible candidate for involvement in the pathogenesis of mood disorder by virtue of its function. Neurotrophins are synthesised in neurons as proforms that can be cleaved intra- or extracellularly and both their synthesis and secretion depends on neuronal activity. BDNF plays an important role in promoting and modifying growth, development and survival of neuronal populations and, in the mature nervous system, it is involved in activitydependent neuronal plasticity (Duman, 1999). These are processes central to the synaptic plasticity hypothesis of mood disorder, which focuses on the functional and structural changes induced by stress and antidepressants at the synaptic level.
It has been specifically hypothesised that mania may be caused by overactivity of central BDNF function (Tsai, 2004).

The BDNF gene lies in the chromosome $11 \mathrm{p} 13$ region, which has been implicated in some linkage studies of bipolar disorder but not in meta-analyses of linkage studies (reviewed in Green \& Craddock, 2004). Thus there is a modest degree of genetic positional evidence to strengthen the functional support for potential $B D N F$ involvement in bipolar disorder. Consistent with the strong evolutionary conservation of the $B D N F$ coding sequence across species, only one common, non-conservative polymorphism in the human $B D N F$ gene has been identified, a single-nucleotide polymorphism at nucleotide 196 within the $5^{\prime}$ pro-BDNF sequence that causes an amino acid substitution of valine to methionine at codon 66 (Val66Met). This is the polymorphism investigated in the current study.

\section{Implications}

Our findings may help to explain some of the variability observed between studies of the BDNF gene in bipolar disorder. Samples of individuals with DSM-IV bipolar disorder may vary substantially in the spectrum of severity of illness and clinical features. For any locus that influences the clinical phenotype rather than simply the overall probability of being in the diagnostic category, there will be variation between sample sets for the estimated effect sizes of the locus. It is important that existing samples that have shown no overall evidence for association between bipolar disorder and variation at $B D N F$ are re-analysed to search for a specific effect with phenotypes related to rapid cycling.

Identification of allelic association is an important step towards implicating a gene within the pathogenesis of a disorder but does not constitute proof of a causal mechanism. The Val66Met polymorphism lies within the proBDNF region of the gene and is not, therefore, translated into the final mature BDNF protein product. However, there is cross-species conservation of the precursor portion of proBDNF. This is consistent with a potential functional importance for this region, perhaps as a signal peptide with an influence on intracellular trafficking and activity-dependent secretion of BDNF (Egan et al, 2003). In vitro studies demonstrated that the Met allele was associated with impaired intracellular trafficking and regulated secretion (Egan et al, 2003). This would be consistent with the hypothesis of BDNF overactivity in mania (Tsai, 2004). Alternatively the polymorphism may be in linkage disequilibrium with one or more pathogenically relevant variants lying close to this genetic location. Further genetic and biological studies are required to differentiate between these possibilities.

In summary, within the largest bipolar disorder genetic association sample studied to date we have found no evidence that variation at the common Val66Met polymorphism of the BDNF gene is associated with susceptibility to bipolar disorder as a whole. However, we obtained significant evidence that the common Val allele is associated with susceptibility to rapid cycling at some stage during illness.

\section{ACKNOWLEDGEMENTS}

This work was funded by grants from the Wellcome Trust. We are grateful to all individuals who participated in this research. We acknowledge use of DNA from the British 1958 birth cohort collection, funded by the Medical Research Council grant G0000934 and the Wellcome Trust grant 068545/2/02.

\section{REFERENCES}

American Psychiatric Association (1994) Diagnostic and Statistical Manual of Mental Disorders (4th edn) (DSM-IV).Washington, DC: APA

Chen, X., Levine, L. \& Kwok, P.Y. (1999)

Fluorescence polarization in homogenous nucleic acid analysis. Genome Research, 9, 492-498.

Craddock, N. \& Jones, I. (1999) Genetics of bipolar disorder. Journal of Medical Genetics, 36, 585-594.

Craddock, N., Jones, I., Kirov, G., et al (2004) The Bipolar Affective Disorder Dimension Scale (BADDS) - a dimensional scale for rating lifetime Psychopathology in bipolar spectrum disorders. BMC Psychiatry, 4, 19

Craddock, N., O'Donovan, M. C. \& Owen, M. J. (2005) Genetics of schizophrenia and bipolar disorder: dissecting psychosis. Journal of Medical Genetics, 42, 288-299.

Duman, R. S. (1999) The neurochemistry of mood disorders: preclinical studies. In The Neurobiology of Mental Illness (eds D. S. Charney, E. J. Nestler \& B. S. Bunney), pp. 333-347. New York: Oxford University Press.

Dunner, D. L. \& Fieve, R. R. (1974) Clinical factors in lithium carbonate prophylaxis failure. Archives of General Psychiatry, 30, 229-233.

Egan, M. F., Kojima, M., Callicott, J. H., et al (2003) The BDNF Val66Met polymorphism affects activitydependent secretion of BDNF and human memory and hippocampal function. Cell, II2, 257-269.

Endicott, J. \& Spitzer, R. L. (1978) A diagnostic interview: the schedule for affective disorders and schizophrenia. Archives of General Psychiatry, 35 837-844. 
Geller, B., Badner, J. A., Tillman, R., et al (2004) Linkage disequilibrium of the brain-derived neurotrophic factor Val66Met polymorphism in children with a prepubertal and early adolescent bipolar disorder phenotype. American Journal of Psychiatry, 161, 1698-1700.

Green, E. \& Craddock, N. (2004) Brain-derived neurotrophic factor as a potential risk locus for bipolar disorder: evidence, limitations, and implications. Current Psychiatry Reports, 5, 469-476.

Hong, C. J., Huo, S. J., Yen, F. C., et al (2003) Association study of a brain-derived neurotrophic factor genetic polymorphism and mood disorders, age of onset and suicidal behavior. Neuropsychobiology, $\mathbf{4 8}$, 186-189.

Kunugi, H., lijima, Y., Tatsumi, M., et al (2004) No association between the Val66Met polymorphism of the brain-derived neurotrophic factor gene and bipolar disorder in a Japanese population: a multicenter study. Biological Psychiatry, 56, 376-378.

Leckman, J. F., Sholomskas, D., Thompson, W. D. et al (1982) Best estimate of lifetime psychiatric

diagnosis: a methodological study. Archives of General Psychiatry, 39, 879-883.

Mackin, P. \& Young, A. H. (2004) Rapid cycling bipolar disorder: historical overview and focus on emerging treatments. Bipolar Disorders, 6, 523-529.

MacKinnon, D. F., Zandi, P. P., Gershon, E., et al (2003) Rapid switching of mood in families with multiple cases of bipolar disorder. Archives of General Psychiatry, 60, $921-928$

Maj, M., Pirozzi, R., Formicola, A. M., et al (1999) Reliability and validity of four alternative definitions of rapid-cycling bipolar disorder. American Journal of Psychiatry, 156, 1421-1424.

McGuffin, P., Farmer, A. \& Harvey, I. (199I) A polydiagnostic application of operational criteria in studies of psychotic illness. Development and reliability of the OPCRIT system. Archives of General Psychiatry, 48, 764-770.

Moskvina, V., Holmans, N., Schmidt, K. M., et al (2005) Design of case-control studies with unscreened controls. Annals of Human Genetics, 69, 566-576.

\section{Müller, D. J., De Luca, V., Sicard, T., et al (2004)} 'Rapid cycling' mainly determines significant findings between the BDNF gene and bipolar disorder. American Journal of Medical Genetics Part B. Neurospychiatric Genetics, I30B, 45.

Müller, D. J., De Luca, V., Sicard, T., et al (2006) The brain derived neurotrophic factor (BDNF) gene and rapid-cycling bipolar disorder. British journal of Psychiatry, in press.

Nakata, K., Ujike, H., Sakai, A., et al (2003) Association study of brain-derived neurotrophic factor (BDNF) gene with bipolar disorder. Neuroscience Letters, 337, 17-20.

Neves-Pereira, M., Mundo, E., Muglia, P., et al (2002) The brain-derived neurotrophic factor gene confers susceptibility to bipolar disorder: evidence from a family-based association study. American journal of Human Genetics, 7I, 65I-655.

Neves-Pereira, M., Cheung, J.K., Pasdar, A., et al (2005) BDNF gene is a risk factor for schizophrenia in a Scottish population. Molecular Psychiatry, 10, 208-212.

\section{CLINICAL IMPLICATIONS}

- Genetic factors are important in influencing susceptibility to clinical subtypes of bipolar disorder.

- The common valine allele at the Val66Met polymorphism within the brain-derived neurotrophic factor gene (BDNF) is associated with increased susceptibility to rapidcycling bipolar disorder.

- This finding will contribute to the understanding of the pathogenesis of bipolar disorder.

\section{LIMITATIONS}

- The finding requires replication to determine the generalisability to other populations.

- The biological mechanism remains to be discovered.

- The finding does not yet have direct clinical applicability.

ELAINE K. GREEN, PhD, RACHEL RAYBOULD, BSc, Department of Psychological Medicine, STUART MACGREGOR, PhD, Biostatistics and Bioinformatics Unit, Wales College of Medicine, Cardiff University, SALLY HYDE, BSc, Division of Neuroscience, University of Birmingham, Queen Elizabeth Psychiatric Hospital, Birmingham, ALLAN H. YOUNG, MD, FRCPsych, Department of Psychiatry, University of Newcastle, MICHAEL C. O'DONOVAN, PhD, FRCPsych, MICHAEL J. OWEN, PhD, FRCPsych, GEORGE KIROV, MD, MRCPsych, Department of Psychological Medicine, Wales College of Medicine, Cardiff University, LISA JONES, $\mathrm{PhD}$, Division of Neuroscience, University of Birmingham, Queen Elizabeth Psychiatric Hospital, Birmingham, IAN JONES, PhD, MRCPsych, NICK CRADDOCK, PhD, FRCPsych, Department of Psychological Medicine, Wales College of Medicine, Cardiff University, Cardiff, Wales, UK

Correspondence: Professor Nick Craddock, Department of Psychological Medicine, Henry Wellcome Building,Wales College of Medicine, Cardiff University, Heath Park, Cardiff CF4 4XN, UK. Tel: +44 (0)2920 744663; fax: +44 (0)2920 746554; e-mail: craddockn@cardiff.ac.uk

(First received I0 February 2005, final revision 7 April 2005, accepted II April 2005)

Nurnberger, J. I. Jr, Blehar, M. C., Kaufmann, C. A. et al (1994) Diagnostic interview for genetic studies. Rationale, unique features, and training. NIMH Genetics Initiative. Archives of General Psychiatry, 5I, 849-859.

Oswald, P., Del-Favero, J., Massat, I., et al (2004) Non-replication of the brain-derived neurotrophic factor (BDNF) association in bipolar affective disorder: a Belgian patient-control study. American Journal of Medical Genetics, I29B, 34-35.

Purcell, S., Cherny, S. S. \& Sham, P. C. (2003) Genetic Power Calculator: design of linkage and association genetic mapping studies of complex traits. Bioinformatics, 19. $149-150$

Skibinska, M., Hauser, J., Czerski, P. M., et al (2004) Association analysis of brain-derived neurotrophic factor (BDNF) gene Val66Met polymorphism in schizophrenia and bipolar affective disorder. World Journal of Biological Psychiatry, 5, 215-220.
Sklar, P., Gabriel, S. B., McInnis, M. G., et al (2002) Family-based association study of 76 candidate genes in bipolar disorder: BDNF is a potential risk locus. Brainderived neurotrophic factor. Molecular Psychiatry, 7 579-593.

Spielman, R. S., McGinnis, R. E. \& Ewens, W. J. (1993) Transmission test for linkage disequilibrium: the insulin gene region and insulin-dependent diabetes mellitus (IDDM). American Journal of Human Genetics, 52, 506-516.

Tsai, S. J. (2004) Is mania caused by overactivity of central brain-derived neurotrophic factor? Medical Hypotheses, 62, 19-22.

Wing, J. K., Babor, T., Brugha, T., et al (1990) SCAN. Schedules for Clinical Assessment in Neuropsychiatry. Archives of General Psychiatry, 47, 589-593. 